\title{
Deployment of a ground-based CIMS apparatus for the detection of organic gases in the boreal forest during the QUEST campaign
}

\author{
K. Sellegri, B. Umann, M. Hanke, and F. Arnold \\ Atmospheric Physic Division, Max Planck Institute for Nuclear Physics, Heidelberg, Germany \\ Received: 26 March 2004 - Published in Atmos. Chem. Phys. Discuss.: 9 July 2004 \\ Revised: 11 January 2005 - Accepted: 25 January 2005 - Published: 8 February 2005
}

\begin{abstract}
Measurements of atmospheric volatile organic compounds were performed in the Finnish Boreal forest atmosphere during spring 2003, as part of the project QUEST (Quantification of Aerosol Nucleation in the European Boundary Layer), using a ground-based Chemical Ionization Mass Spectrometer (CIMS) instrument. Based on the study of their hydrate distribution, methanol, acetonitrile, acetaldehyde, dimethyl amine (DMA), ethanol/formic acid, acetone, trimethyl amine (TMA), propanol/acetic acid, isoprene, methyl vinyl ketone (MVK) and metacrolein (MaCR), monoterpenes and monoterpene oxidation product (MTOP) are proposed as candidates for masses 32, 41, 44, 45, 46, $58,59,60,68,70,136$, and $168 \mathrm{amu}$, respectively. It would be, to our knowledge, the first time DMA, TMA and MTOP are measured with this method. Most compounds show a clear diurnal variation with a maximum in the early night, corresponding to the onset of the noctural inversion and in agreement with independant measurements of CO. Biogenic compounds are highly correlated with each other and the ratio monoterpene/oxidation product shows a typical daily pattern of nightime maxima. However, because isoprene mixing ratios are also maximum during the early night, it is likely that it suffers of the interference from another unidentified biogenic compound. Hence mass 68 amu is identified as isoprene+compound $\mathrm{X}$.
\end{abstract}

\section{Introduction}

Vast quantities of biogenic hydrocarbons are emitted to the atmosphere by vegetation, having an impact both on the atmospheric chemistry at local, regional and global scale, and on atmospheric processes such as new particle formation and growth. The amount of emissions of natural nonmethane hy-

Correspondence to: K. Sellegri

(K.Sellegri@opgc.univ-bpclemront.fr) drocarbons (NMHC) are estimated to be higher than those of anthropogenic NMHC (Guenther et al., 1995), and their oxidation products may be the greatest natural continental source of fine particles. Hoffman et al. (1997) suggested that at night the products from ozonolysis of pinene were of sufficiently low vapor pressures to condense freely on existing particles or possibly homogeneously nucleate, which makes daily variations studies important. Also, high resolution time series of biogenic gases concentrations bring new information for the understanding of how NMHC are oxidized in a natural atmosphere and how their ambient concentrations are driven by the dynamic of the boundary layer.

In this paper, we present the results of measurements of atmospheric volatile organic compounds (VOC) in the Finnish Boreal forest atmosphere during spring 2003, as part of the project QUEST (Quantification of Aerosol Nucleation in the European Boundary Layer), using a ground-based Chemical Ionization Mass Spectrometer (CIMS) instrument. Monoterpenes have already been measured at the site by means of adsorbent cartridges and GC-FID (Hakola et al., 2000) or GC-MS (Spirig et al., 2003). The advantages of the CIMS instrument over cartridge sampling associated to gas chromatographic analysis is the fast time response of a few seconds and the online detection of reactive species that might be modified otherwise. If integrated over several minutes, which still allow for the study of relatively fast changing atmospheric concentrations, a low detection limit down to less than $10 \mathrm{ppt}$ for some trace gases can also be achieved. CIMS has been previously used for the air-borned measurements of organic gases (Arnold et al., 1997; Wohlfrom et al., 1999; Schröder et al., 2003). The ground-based adaptation of the CIMS apparatus for the measurement of organic gases provides a set of on-line data over extended periods of time, and unables the study of high time resolution daily variations. The chemical ionization (CI) technique involved in the CIMS instrument uses ion-molecule reactions which cause much less fragmentation than electron impact or photoionization.

(C) 2005 Author(s). This work is licensed under a Creative Commons License. 
However, ion identification is still a problem when the ionized molecules are hydrated with several water clusters. The goal of this paper is mainly to address all atmospheric candidates for the gases detected during the Quest campaign with CIMS. Furthermore, daily variation of the measured species are observed, and used as a validation tool for the consistency of the data set. Hence, we report mixing ratios time variation of a large variaty of species (some of them being measured for the first time with this technique) as the result of the first ground-based CIMS operated for measurement of organic gases.

\section{Site and Instrumental deployment}

The SMEAR experimental station (Station for Measuring Forest Ecosystem-Atmosphere Relations) located in Hyytiälä, southern Finland $\left(61^{\circ} 51^{\circ} \mathrm{N}, 24^{\circ} 17 \mathrm{E}, 181 \mathrm{~m}\right.$ above sea level) is representative of the boreal coniferous forest. A complete description of the site can be found elsewhere (Kulmala et al., 2001). Data presented in this paper are based on samplings achieved during 2 weeks: from 17 to 29 March 2003. Gas measurements have been sampled from an adapted measuring container located $50 \mathrm{~m}$ south-west of the SMEAR station, at $2.5 \mathrm{~m}$ above the ground. The comparison of water vapor measurements obtained with the CIMS set up with the water vapor measured at the station $(4.2 \mathrm{~m})$ show excellent agreement (less than 5\% disagreement). This indicates that the location of the measurement container is suitable for comparison of the CIMS results with the SMEAR data set. In order to avoid wall effects and sampling of fine particles, the measuring container was equipped with a large diameter-high velocity inlet, in which the sampling line was installed perpendicularly to the inlet flux (Hanke et al., 2003). The inlet protrudes about $1 \mathrm{~m}$ above the roof of the container, so that the air should not have encountered any surface before being drawn into the sampling line.

Measurements were performed using a Chemical Ionization Mass Spectrometer (CIMS) instrumental set-up, based on ion-molecule reaction for the detection of trace gases. The instrument, which was designed by the MPIK-Heidelberg, is composed of (a) the high velocity inlet mentionned above (b) a sampling line equipped with a critical orifice and thermostatted at $\sim 30^{\circ} \mathrm{C}$, (c) an ion source, generating $\mathrm{H}_{3} \mathrm{O}^{+}\left(\mathrm{H}_{2} \mathrm{O}\right)_{n}$ educts ions (d) a flow tube reactor, also thermostatted at $\sim 30^{\circ} \mathrm{C}$, in which educts ions react with the atmospheric gases to be analyzed (e) a quadrupole mass spectrometer for the detection of ionized gas molecules (Fig. 1). A similar experimental set-up has been used by MPIK-HD for previous atmospheric trace gas measurements and is described in detail elsewhere (Hanke et al., 2003). Briefly, atmospheric air enters the critical orifice, which assures a constant flow rate of about $10 \mathrm{slpm}$ (also measured with two anemometers further in the sampling line) and a pressure of 10 mbars, created by using two oil-free SCROLL vac- uum pumps. Educt ions $\mathrm{H}_{3} \mathrm{O}^{+}$are produced by a highfrequency glow-discharge capillary-tube ion source (CIS) and a $2 \operatorname{sim~} \mathrm{O}_{2}$ source gas flow: $\mathrm{O}_{2}^{+}$ions produced from the CIS rapidly react with the more abundant atmospheric $\mathrm{H}_{2} \mathrm{O}$ to give $\mathrm{H}_{3} \mathrm{O}^{+}$. Hydration of the $\mathrm{H}_{3} \mathrm{O}^{+}$reactant ions occurs by association with water vapor in the main flow tube, leading to a distribution of $\mathrm{H}_{3} \mathrm{O}^{+}\left(\mathrm{H}_{2} \mathrm{O}\right)_{n}$ ions, with $\mathrm{n}$ from 0 to 6 , of which the ions with $n=3$ are most abondant. Then, as a first approximation of the complex chemistry involved, it is calculated that atmospheric gases $\mathrm{X}$ with proton affinities larger than that of $\mathrm{H}_{2} \mathrm{O}\left(166.5 \mathrm{kcal} \mathrm{mol}^{-1}\right)$ react in the flow tube reactor with educt ions $\mathrm{H}_{3} \mathrm{O}^{+}\left(\mathrm{H}_{2} \mathrm{O}\right)_{n}$ via:

$\mathrm{H}_{3} \mathrm{O}^{+}\left(\mathrm{H}_{2} \mathrm{O}\right)_{n}+\mathrm{X} \rightarrow \mathrm{HX}^{+}\left(\mathrm{H}_{2} \mathrm{O}\right)_{n}+\mathrm{H}_{2} \mathrm{O}$

Thus, also the product ions are hydrated with up to 6 water molecules. Depending on the number of water ligants and on the molecule $\mathrm{X}$ proton affinity (PA), also a backward reaction is possible (Viggiano et al., 1988):

$\mathrm{HX}^{+}\left(\mathrm{H}_{2} \mathrm{O}\right)_{n}+\mathrm{H}_{2} \mathrm{O} \rightarrow \mathrm{H}_{3} \mathrm{O}^{+}\left(\mathrm{H}_{2} \mathrm{O}\right)_{n}+\mathrm{X}$

The lower the PA of molecule X, the more important the reverse reaction. In our experimental set-up, we intentionally lowered the total gas pressure in the flow tube reactor to $10 \mathrm{mbar}$ (compared to the previous use of $50 \mathrm{mbar}$ ), in order to reduce the occurrence of reverse reactions, which will specifically be addressed later. The residence time in the flow tube reactor is much longer then the reaction time for a collision rate $\left(2.3 \times 10^{-9} \mathrm{~cm}^{3} \mathrm{~s}^{-1}\right)$, allowing the atmospheric gases to react during traveling in the flow tube reactor. Both products and excess educt ions enter the quadrupole mass spectrometer where they are selected according to their mass. One mass scan (for ion masses from 10 to $200 \mathrm{amu}$ ) lasts $3.2 \mathrm{~s}$. For improving the detection limit of organic trace gases, an integration time of 100 to 200 successive scans has been chosen, leading to a time resolution of 320 to $640 \mathrm{~s}$.

The concentration of the atmospheric gas $\mathrm{Xi}$ is obtained from the count rate of $\mathrm{Xi}$, the count rate of the educt ion $\mathrm{H}_{3} \mathrm{O}^{+}$and of the sum of all product ions $\Sigma \mathrm{Xj}$, the measured reaction time $\tau$ between the ion source and the detector, and the collision rate constant $k\left(2.3 \times 10^{-9} \mathrm{~cm}^{3} \mathrm{~s}^{-1}\right)$ of the ionmolecule reaction (parallel Acims-formula) according to:

$$
\begin{aligned}
& {[\mathrm{Xi}]=(k * \tau)^{-1} \mathrm{Xi}\left(\mathrm{H}_{2} \mathrm{O}\right)_{n} / \Sigma \mathrm{Xj}\left(\mathrm{H}_{2} \mathrm{O}\right)_{n} *} \\
& \ln \left[1+\Sigma \mathrm{Xj}\left(\mathrm{H}_{2} \mathrm{O}\right)_{n} / \mathrm{H}_{3} \mathrm{O}^{+}\left(\mathrm{H}_{2} \mathrm{O}\right)_{n}\right]
\end{aligned}
$$

Where $\mathrm{Xi}\left(\mathrm{H}_{2} \mathrm{O}\right)_{n}, \mathrm{Xj}\left(\mathrm{H}_{2} \mathrm{O}\right)_{n}$ and $\mathrm{H}_{3} \mathrm{O}^{+}\left(\mathrm{H}_{2} \mathrm{O}\right)_{n}$ are the sum of count rates of all hydrates from $n=1$ to $n=5$ when possible (see Sect. 3). How many hydrates are taken into account will be discussed for each compound in Sect. 3. This mixing ratio calculation does not take into account diffusion and sticking of gases onto the sampling tube walls, reverse reactions and mass discrimination in the mass spectrometer. In order to take those parameters, as well as uncertainties on reaction rate constants into account, in-situ calibrations were performed for acetonitrile, acetaldehyde, methanol, isoprene 


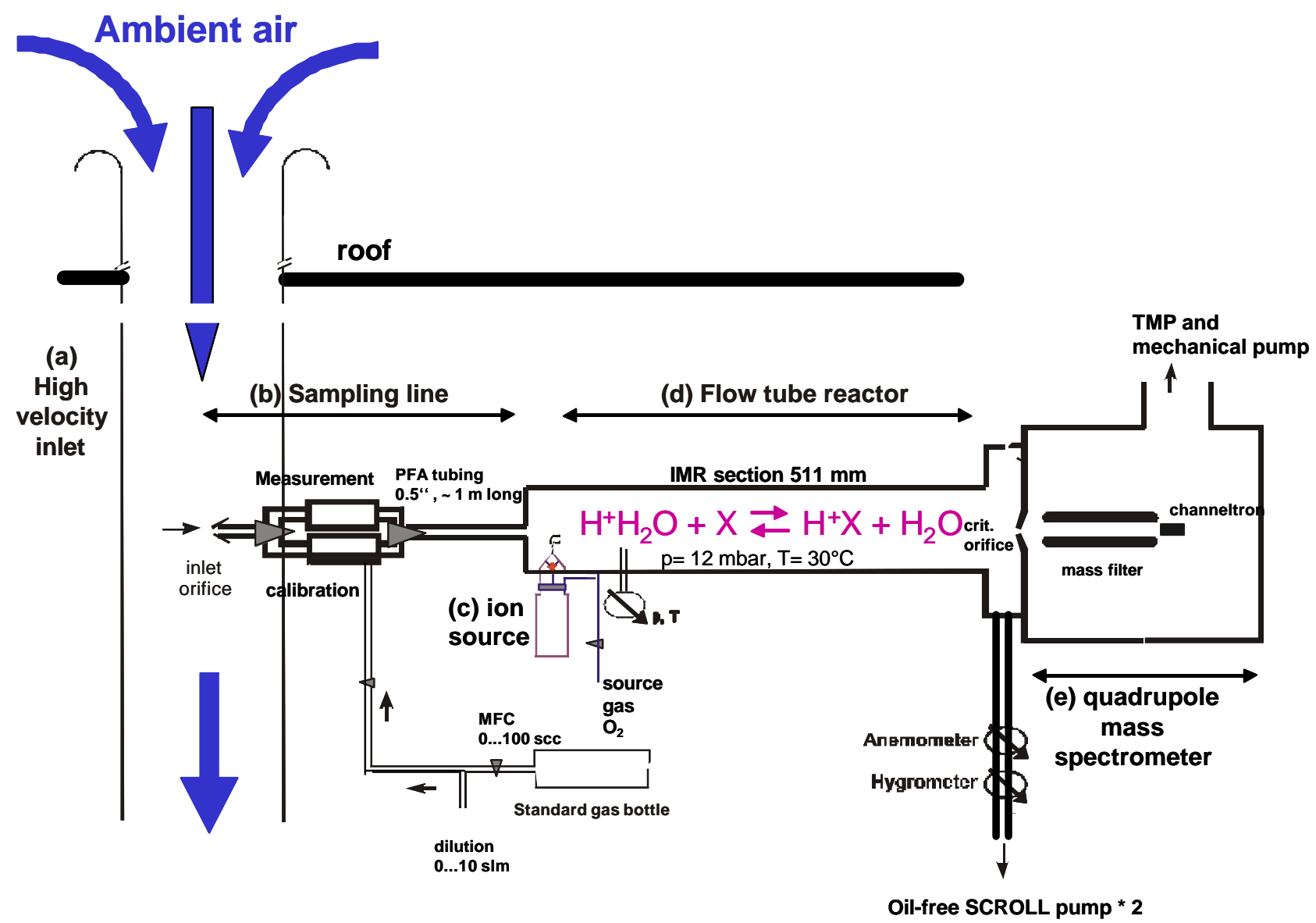

Fig. 1. Experimental set up: schematic view of the CIMS instrument. (a) high velocity inlet (b) critical orifice and sampling line (c) ion source, generating $\mathrm{H}_{3} \mathrm{O}^{+}\left(\mathrm{H}_{2} \mathrm{O}\right)_{n}$ educts ions (d) flow tube reactor (e) quadrupole mass spectrometer.

and DMA. Calibrations were performed on-line during measurements using gas bottle standards (one standard gas bottle contained a mixture of acetonitrile, acetaldehyde, methanol, isoprene, while another one contained DMA), both in zero air and in atmospheric air in order to evaluate the influence of other atmospheric gases on the calibration. Zero air levels are obtained using a commercial zero air generator (Breitfuss $\mathrm{GmbH}$ ) by passing atmospheric air through a catalyst at $450^{\circ} \mathrm{C}$ and quenshing the water, with a frequency of about an hour per two days.

\section{Ion identification}

An example of the mass spectra obtained during the campaign is shown Fig. 2. The sensitivity of the instrument was raised to the maximum in order to obtain the best detection limit within our experimental set up. However, a high sensitivity induced a lower mass resolution. This can be seen on Fig. 2 in the proximity of the educt ion peaks (especially 73 $\left(\mathrm{H}_{3} \mathrm{O}^{+}\left(\mathrm{H}_{2} \mathrm{O}\right)_{3}\right)$ and $\left.91 \mathrm{amu}\left(\mathrm{H}_{3} \mathrm{O}^{+}\left(\mathrm{H}_{2} \mathrm{O}\right)_{4}\right)\right)$. Peaks from ions 1 amu smaller or larger then the educt ions and hydrates

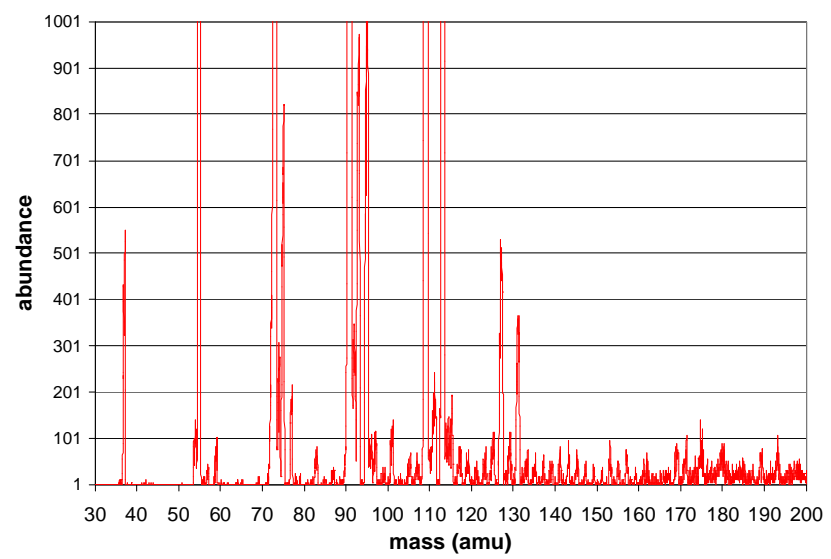

Fig. 2. Example of the mass spectra obtained during the atmospheric measurements.

could not always be reliably separated from the educt ions peaks. This is the case for masses 72, 90, and 108 . 
Table 1. Monitored mass numbers of ions X, sorted by hydrate families in the form of $\mathrm{HX}^{+}\left(\mathrm{H}_{2} \mathrm{O}\right)_{n}$. between brackets are the ions which peaks have not always been correctly separated from the reactant peaks. Underlined are the masses for which the count rate was maximum within the peak family.

\begin{tabular}{|c|c|c|c|c|c|c|c|c|}
\hline Core ion $\mathrm{HX}^{+}$ & $\mathrm{HX}^{+}\left(\mathrm{H}_{2} \mathrm{O}\right)$ & $\mathrm{HX}^{+}\left(\mathrm{H}_{2} \mathrm{O}\right)_{2}$ & $\mathrm{HX}^{+}\left(\mathrm{H}_{2} \mathrm{O}\right)_{3}$ & $\mathrm{HX}^{+}\left(\mathrm{H}_{2} \mathrm{O}\right)_{4}$ & $\mathrm{HX}^{+}\left(\mathrm{H}_{2} \mathrm{O}\right)_{5}$ & $\mathrm{HX}^{+}\left(\mathrm{H}_{2} \mathrm{O}\right)_{6}$ & $\mathrm{HX}^{+}\left(\mathrm{H}_{2} \mathrm{O}\right)_{7}$ & $\mathrm{HX}^{+}\left(\mathrm{H}_{2} \mathrm{O}\right)_{8}$ \\
\hline 18 & 36 & 54 & (72) & (90) & (108) & 126 & 144 & 162 \\
\hline 19 & 37 & 55 & 73 & 91 & 109 & 127 & 145 & 163 \\
\hline 33 & 51 & 69 & $\overline{87}$ & 105 & 123 & 141 & 159 & 177 \\
\hline 42 & 60 & $\overline{78}$ & 96 & 114 & 132 & $\overline{150}$ & 168 & $\overline{186}$ \\
\hline 45 & $\underline{63}$ & 81 & 99 & $\overline{117}$ & 135 & 153 & $\underline{171}$ & 189 \\
\hline 46 & $\overline{64}$ & 82 & 100 & 118 & 136 & 154 & $\overline{172}$ & \\
\hline 47 & $\overline{65}$ & $\underline{83}$ & 101 & 119 & 137 & 155 & $\overline{173}$ & \\
\hline 49 & 67 & $\overline{85}$ & 103 & $\underline{121}$ & 139 & $\underline{157}$ & $\overline{175}$ & \\
\hline 59 & 77 & 95 & 113 & $\overline{131}$ & 149 & $\overline{167}$ & $\overline{185}$ & \\
\hline 61 & 79 & $\underline{97}$ & 115 & 133 & 151 & $\overline{169}$ & 187 & \\
\hline 71 & 89 & 107 & $\underline{125}$ & 143 & 161 & $\overline{179}$ & & \\
\hline
\end{tabular}

Table 2. Some chemical and physical properties of measured compounds; sulfuric acid and $\mathrm{NH}_{3}$ properties are also indicated for comparison. Ref: Handbook of Chemistry and Physics for proton affinities. Life time order of magnitude, Williams et al. (2000) for acetone, acetonitrile, acetaldehyde, isoprene, methan, using $\mathrm{OH}=5 \times 10^{5}$ molecules $\mathrm{cm}^{-3}$ and Atkinson (1994) for pinene, MVK and MACR using $\mathrm{OH}=1 \times 10^{6}$ molecules $\mathrm{cm}^{-3}$ and ozone $=40 \mathrm{ppbv}$.

\begin{tabular}{|c|c|c|c|c|}
\hline Compound & $\begin{array}{l}\text { Molecular Mass } \\
\text { Number }\end{array}$ & $\begin{array}{l}\text { Proton affinity } \\
\mathrm{kcal} \mathrm{mol}^{-1}\end{array}$ & Structure & $\begin{array}{l}\text { Order magnitude } \\
\text { Life time }(/ \mathrm{OH}+\mathrm{h} v)\end{array}$ \\
\hline acetone & 58 & 188 & $\mathrm{CH}_{3} \mathrm{COCH}_{3}$ & 1 month \\
\hline acetonitrile & 41 & 186 & $\mathrm{CH}_{3} \mathrm{CN}$ & 3 years \\
\hline acetaldehyde & 44 & 185 & $\mathrm{CH}_{3} \mathrm{CHO}$ & 1 day \\
\hline isoprene & 68 & 197 & $\mathrm{CH}_{2}=\mathrm{C}\left(\mathrm{CH}_{3}\right) \mathrm{CH}=\mathrm{CH}_{2}$ & 6 hours \\
\hline methanol & 32 & 180 & $\mathrm{CH}_{3} \mathrm{OH}$ & 1 month \\
\hline DMA & 45 & $218-225$ & $\mathrm{CH}_{3}-\mathrm{NH}-\mathrm{CH}_{3}$ & - \\
\hline TMA & 59 & $222-230$ & $\mathrm{CH}_{3}-\mathrm{N}\left(\mathrm{CH}_{3}\right)-\mathrm{CH}_{3}$ & - \\
\hline ethanol & 46 & 185.5 & $\mathrm{CH}_{3} \mathrm{CH}_{2} \mathrm{OH}$ & - \\
\hline formic acid & 46 & 178 & $\mathrm{H}-\mathrm{COOH}$ & - \\
\hline propanol & 60 & 189.4 & $\mathrm{CH}_{3}-\mathrm{CH}_{2}-\mathrm{CH}_{2} \mathrm{OH}$ & - \\
\hline acetic acid & 60 & 188 & $\mathrm{CH}_{3}-\mathrm{COOH}$ & - \\
\hline pinonaldehyde & 168 & - & $\mathrm{C}_{10} \mathrm{H}_{16} \mathrm{O}_{2}$ & - \\
\hline $\begin{array}{l}\text { methyl vinyl ketone/ } \\
\text { methacrolein }\end{array}$ & 70 & 199/193 & $\begin{array}{l}\mathrm{CH}_{2}=\mathrm{CH}-\mathrm{CO}-\mathrm{CH}_{3} / \\
\mathrm{CH}_{2}=\mathrm{C}\left(\mathrm{CH}_{3}\right)-\mathrm{CH}=\mathrm{O}\end{array}$ & $\begin{array}{l}\mathrm{vsOH}=15 / 8 \text { hours } \\
\mathrm{vsO}_{3}=62 / 248 \text { hours }\end{array}$ \\
\hline $\begin{array}{l}\alpha \text {-pinene/ } \\
\beta \text {-pinene }\end{array}$ & 136 & - & $\mathrm{C}_{10} \mathrm{H}_{16}$ & $\begin{array}{l}\mathrm{vsOH}=5 / 3.5 \text { hours } \\
\mathrm{vsO}_{3}=3 / 19 \text { hours }\end{array}$ \\
\hline
\end{tabular}

We monitored the acquisition of the ion masses summarized in Table 1, sorted by peak families: as already mentioned, core ions $\mathrm{XH}^{+}$can be hydrated with several water molecules and thus be detected at masses higher by several multiples of $18 \mathrm{amu}$ than their original core ion mass. Consequently, at one mass, there can be a contribution of the types $\mathrm{XH}^{+}, \mathrm{Y}\left(\mathrm{H}_{2} \mathrm{O}\right) \mathrm{H}^{+}$, or $\mathrm{Z}\left(\mathrm{H}_{2} \mathrm{O}\right)_{2} \mathrm{H}^{+}$etc. Therefore, one mass can be the signature, not only of different compounds having the same mass as $X$ (isomeres), but also of compound having the mass of $\mathrm{Y}, \mathrm{Z}$, etc. In order to distinguish one compound from the other, the count rates of clusters versus the number of hydrates associated to the core mass are studied. Distributions obtained are shown Fig. 3 for the driest and the wettest day of the campaign (20/03/2003 with a water vapor mole fraction of 2000-2500 ppm and 23/03/2003 with $6500 \mathrm{ppm}$ ), as well as for the calibration tests when available (i.e. for DMA, acetonitrile, acetaldehyde, methanol and isoprene). For the reactant ion $\mathrm{H}_{3} \mathrm{O}^{+}$, the maximum count rate is observed for $\mathrm{H}_{3} \mathrm{O}^{+}\left(\mathrm{H}_{2} \mathrm{O}\right)_{n}$ clusters with $n=3$. Because hydronium ions have hydration enthalpies larger than any other ion species (Keesee et al., 1986), and $\mathrm{H}_{2} \mathrm{O}$ exchange reactions are fast compared to the ion-molecule reactions with 

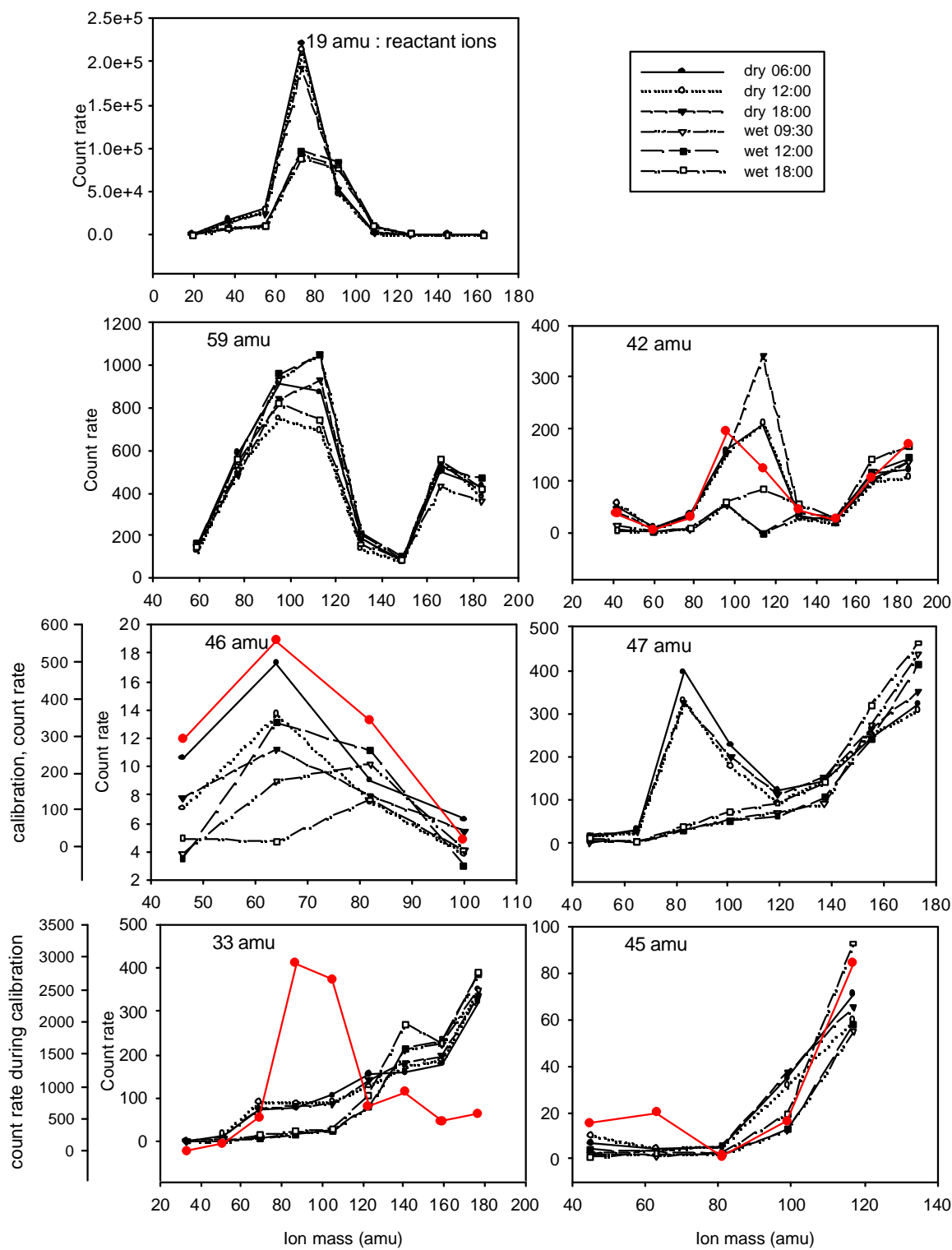

Fig. 3. Count rates plotted against the increasing hydration states of the core ions, averaged over different times in the day for the driest and wettest days of the campaign. Red curves are for calibrations with standard bottles when possible.

trace gases of interest (Wohlfrom, 2000), maximum count rates for other species than $\mathrm{H}_{3} \mathrm{O}^{+}$are observed for $\mathrm{n}$ equal to or lower than 3 . This observation is confirmed during calibrations of acetonitrile, acetaldehyde, methanol, isoprene and DMA, when the count rates show a maximum for $n=3,1,3$, 2 and 1 respectively in a $4000 \mathrm{ppm}$ water content air, and also for acetone which shows a maximum count rate for $n=2$ or 3 depending on humidity.

Because $33 \mathrm{amu}, 42 \mathrm{amu}, 45 \mathrm{amu}$, and $46 \mathrm{amu}$ are relatively low molecular masses, atmospheric compounds which are a combination of $\mathrm{C}, \mathrm{O}, \mathrm{N}$ and $\mathrm{H}$ with a higher proton affinity than the one of water (Table 2), which are candidates for these masses are of limited number. For these four masses, candidates are respectively protonated methanol, acetonitrile, acetaldehyde and DMA, and we did not find any other compound with the required characteristics mentioned above that could interfere at the same masses.

Atmospheric hydrate distributions of the peak families corresponding to mass $33 \mathrm{amu}$ show a maximum count rate plateau on masses 69, 87 and 105 amu. During calibration of methanol and isoprene with a ratio of $1: 1$, we also observed a maximum for masses 87 and 105. These masses would correspond to $\left(\mathrm{H}^{+}\right.$methanol $\left.\left(\mathrm{H}_{2} \mathrm{O}\right)_{3,4}\right)$ or to $\mathrm{H}^{+}$isoprene $\left(\mathrm{H}_{2} \mathrm{O}\right)_{1,2}$. Thus masses 69 and $87 \mathrm{amu}$ are expected to be mostly rerpresentative of methanol, and mass $105 \mathrm{amu}$ is expected to be mostly rerpresentative of Isoprene. 
water dependence of 78, 96 and 114 amu during calibration of acetonitrile

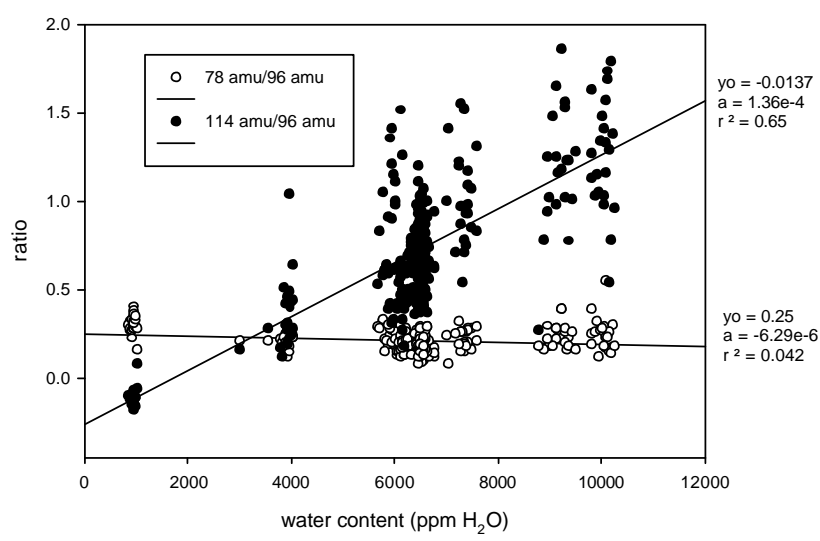

Fig. 4. Ratios of 96/114 and 96/78 amu versus water content of the analyzed air mass during calibration of acetonitrile.

Consequently, calculation of the methanol concentration will be based on masses 51, 69, and $87 \mathrm{amu}$, while isoprene concentrations will be calculated on the basis of masses 105 , 123 and 141 (Table 3). In fact, mass 141 is occasionally also a maximum count rate in this peak family, and it would stand for $\mathrm{H}^{+}$isoprene $\left(\mathrm{H}_{2} \mathrm{O}\right)_{4}$, which should be smaller than $\mathrm{H}^{+}$isoprene $\left(\mathrm{H}_{2} \mathrm{O}\right)_{3}$. Another candidate in this peak family is 2-methyl-3-buten-2-ol (hereafter refered as MBO) which protonated mass is 87 , and that could contribute to the same masses as isoprene. $\mathrm{MBO}$ is also a biogenic hydrocarbon that has already been measured in the ambient air of a pine forests (Goldan et al., 1993; Spaulding et al., 2003) and in a subalpine forest by Karl et al. (2002). Measurements of MBO interfere with measurements of isoprene in the PTRMS method as well (Karl et al., 2002). However, the pine species found in Hyytiala are not MBO-emitting species and $\mathrm{MBO}$ will not be considered to contribute to the mass $69 \mathrm{amu}$ mixing ratios.

Atmospheric hydrate distributions of the peak families corresponding to mass $42 \mathrm{amu}$ (acetonitrile, $\mathrm{CH}_{3} \mathrm{CN}$ ) show a maximum count rate at $114 \mathrm{amu}$, which would correspond to $\left(\mathrm{H}^{+}\right.$acetonitrile $\left.\left(\mathrm{H}_{2} \mathrm{O}\right)_{4}\right)$. During calibration of acetonitrile though, a maximum count rate is observed for $96 \mathrm{amu}$, corresponding to $\mathrm{H}^{+}$acetonitrile $\left(\mathrm{H}_{2} \mathrm{O}\right)_{3}$. This would indicate that a compound with a mass of the type $41+x 18 \mathrm{amu}$ (where x could be 1,2 or 3) is actually measured in the atmosphere and overlapping acetonitrile hydrate distribution. The protonated compound $\mathrm{X}$ which would give a maximum count rate at $114 \mathrm{amu}$ in atmospheric air for $n=3$ (i.e. in the form $\left.\mathrm{H}^{+} \mathrm{X}\left(\mathrm{H}_{2} \mathrm{O}\right)_{3}\right)$ would have the mass $60 \mathrm{amu}$. The candidate for this mass is trimethyl amine (TMA). Once respectively protonated and hydrated, TMA (59 amu) and acetonitrile (41 amu) have both a signature at $60 \mathrm{amu}$, and furthermore at $78 \mathrm{amu}$ and $96 \mathrm{amu}$. For the calculation of their re- spective mixing ratio, we have, during calibration of acetonitrile in zero air (where TMA mixing ratios were less than $10 \mathrm{ppt}$ ), calculated the ratio of $\mathrm{H}^{+} \mathrm{CH}_{3} \mathrm{CN}\left(\mathrm{H}_{2} \mathrm{O}\right)_{3}$ (mass 96) to $\mathrm{H}^{+} \mathrm{CH}_{3} \mathrm{CN}\left(\mathrm{H}_{2} \mathrm{O}\right)_{2}$ (mass 78) and $\mathrm{H}^{+} \mathrm{CH}_{3} \mathrm{CN}\left(\mathrm{H}_{2} \mathrm{O}\right)_{4}$ (mass 114) for different water vapor contents. We obtain a "shape" of clustering hydrate distribution of $\mathrm{CH}_{3} \mathrm{CN}$ for different relative humidity. Ratios of mass 96 to masses 114 and $78 \mathrm{amu}$ are proportional to the water content, as shown Fig. 4. Thus, for calculation of respectively acetonitrile and TMA mixing ratio in atmospheric air, the shape clustering hydrate distribution of $\mathrm{CH}_{3} \mathrm{CN}$ for different relative humidity is assumed to be the same as for calibrations. Then, the contribution of acetonitrile to mass 96 amu is calculated from the count rate ratio mass $78 /$ mass 96 (Fig. 4) measured during calibrations of acetonitrile, $78 \mathrm{amu}$ presumably all due to acetonitrile. Once calculated, the contribution of acetonitrile to mass 96 is subtracted from the measured count rate of mass 96 in order to obtain the contribution from TMA to this mass. The same procedure is applied for mass $114 \mathrm{amu}$. After calculation, we did not find any correlation or anticorrelation between acetonitrile and TMA or acetonitrile and $\mathrm{H}_{2} \mathrm{O}$ or TMA and $\mathrm{H}_{2} \mathrm{O}$, indicating that there was no bias in the calculation and that both compounds are clearly distinct from each other.

Atmospheric hydrate distributions of the peak families corresponding to mass $45 \mathrm{amu}$ do not show a clear maximum count rate in atmospheric air, but do show a maximum count rate during calibration of acetaldehyde for $63 \mathrm{amu}$, corresponding to $\mathrm{H}^{+}$acetaldehyde $\left(\mathrm{H}_{2} \mathrm{O}\right)$. Count rates raise again after mass 81 amu (Fig. 3), indicating that a compound different from acetaldehyde is responsible for these count rates, and only masses 45, 63 and 81 were taken into account in the acetaldehyde mixing ratio calculation.

Atmospheric hydrate distributions of mass $46 \mathrm{amu}$ (DMA) show a maximum count rate for mass $64 \mathrm{amu}$, which corresponds to $\left(\mathrm{DMA}\left(\mathrm{H}_{2} \mathrm{O}\right)\right)$, in agreement with the hydrate distributions of calibrated DMA.

Both protonated ethanol and formic acid are candidates for mass 47 amu. Respective proton affinities of ethanol and formic acid are 185.5 and $178 \mathrm{kcal} \mathrm{mol}^{-1}$ (Table 3), which are similar. Thus it is difficult to distinguish between the two compounds from their hydration, which shows a maximum count rate at $n=2$. Also Lindinger et al. (1998) found both compounds with a signature $47 \mathrm{amu}$. Similarly, protonated propanol or acetic acid are candidates for mass $61 \mathrm{amu}$, with respective proton affinities of 189.4 and $188 \mathrm{kcal} \mathrm{mol}^{-1}$. However, Lindinger et al. (1998) found that while acetic acid has a signature at $61 \mathrm{amu}$ (in the regular protonated form $\mathrm{HX}+$ ), Propan-1ol and Propan-2-ol have a signature at $43 \mathrm{amu}$, corresponding to the loss of a molecule of $\mathrm{H}_{2} \mathrm{O}$. In this study, hydrate distributions in atmospheric air show a maximum count rate at $\mathrm{m}=97 \mathrm{amu}$ wich would stand for $\operatorname{propanol}\left(\mathrm{H}_{3} \mathrm{O}^{+}\right)_{2}$ or acetic $\operatorname{acid}\left(\mathrm{H}_{3} \mathrm{O}^{+}\right)_{2}$.

Possible contributors to mass $59 \mathrm{amu}$ include acetone, propanal and glyoxal. Propanal have been excluded by PIT- 
Table 3. Masses taken into account for MR calculation.

\begin{tabular}{|c|c|c|c|c|c|c|c|}
\hline & acetone & acetonitrile & acetal & TMA & DMA & methanol & ethanol/formic acid \\
\hline
\end{tabular}

\begin{tabular}{llllll}
\hline & propanol/acetic acid & isoprene & MVK/MACR (70) & monoterpenes (136) & MTOP (168) \\
\hline Masses (amu) & $61 ; 79 ; 97 ; 115$ & $105 ; 123 ; 141$ & $71 ; 89 ; 107$ & $137 ; 155$ & $169 ; 187$ \\
& & $125 ; 143$ & 173 & & \\
\hline
\end{tabular}

MAS studies in aircraft-based atmospheric measurements (Shröder et al., 2003). Glyoxal has a short atmospheric lifetime due to rapid photolysis, and the variability of the signal associated to mass $59 \mathrm{amu}$ shows a lifetime close to the lifetime of acetone. Hydrate distribution of the peak serie of mass59 shows a maximum count rate for $n=2$ clusters for the driest day, and for $n=3$ clusters for the wettest day. Consequently, count rates of masses 59, 77, 95, 113 and $131 \mathrm{amu}$ are taken into account to calculate the acetone concentration according to Eq. (3).

Possible contributors to mass 69 include protonated isoprene, cyclopentene, and furan. Candidates for mass $71 \mathrm{amu}$ are protonated methyl vinyl ketone and methacrolein, hereafter referred as MVK/MaCR, which are both oxidation products from isoprene (Williams et al., 2000). Correlation between mass 69 amu and mass $71 \mathrm{amu}$ are highly significant during the QUEST campaign (Fig. 5a). Good correlation was also observed between isoprene and MVK+MACR with an airborne PTR-MS (Warneke et al., 2001). Consequently, at this stage, we propose isoprene as a candidate for mass $69 \mathrm{amu}$, and the sum of MVK and MaCR, as oxidation products of isoprene for mass $71 \mathrm{amu}$.

A maximum count rate is observed for mass $169 \mathrm{amu}$, leading to high mixing ratios for the compound contributing to this mass. The contribution to mass $169 \mathrm{amu}$ can be of the types $\mathrm{XH}+, \mathrm{Y}\left(\mathrm{H}_{2} \mathrm{O}\right) \mathrm{H}+$ or $\mathrm{Z}\left(\mathrm{H}_{2} \mathrm{O}\right)_{2} \mathrm{H}+$, where $\mathrm{Z}$ is $132 \mathrm{amu}$, $\mathrm{Y}$ is $150 \mathrm{amu}$ and $\mathrm{X}$ is $168 \mathrm{amu}$. For each of the compounds $\mathrm{X}, \mathrm{Y}$ and $\mathrm{Z}$, a candidate was investigated:

- A possible contributor for $132 \mathrm{amu}$ is glutaric acid. With a molecular structure containing to carboxyl groups, glutaric acid has a high potential to form hydrogen bonds. However, there is little information on the proton affinity of this compound. We tested its capacity to be measured with the CIMS instrument by injecting vapours of a $1 \%$ aqueous solution of glutaric acid into a proton transfer instrument (PITMAS). No signature of glutaric vapours was found in the PITMAS spectra, indicating that its proton affinity is not high enough to be measured with this method.
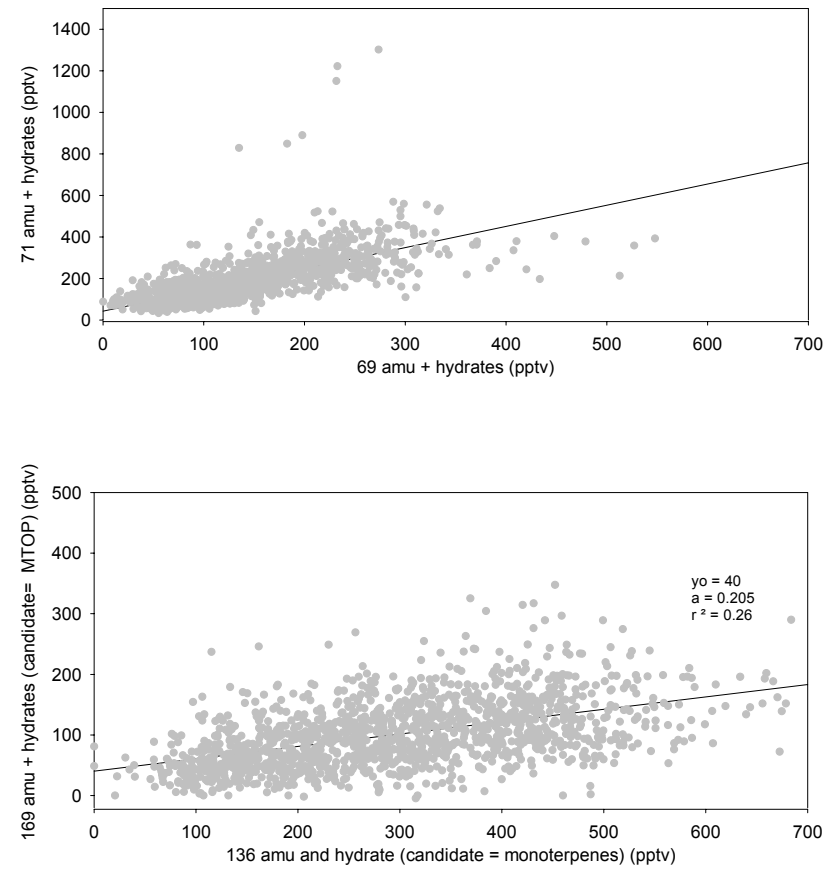

Fig. 5. (a) Correlation between the total count rate of mass $69 \mathrm{amu}$ and hydrates (candidate is isoprene) and mass $71 \mathrm{amu}$ and hydrates (candidates are MVK and MaCR) (b) Correlation between the total count rate of mass $137 \mathrm{amu}$ and hydrates (candidate is monoterpenes) and mass 169 amu and hydrates (candidates are pinonaldehyde and other monoterpene oxidation products MTOP).

- We did not find any combination of $\mathrm{C}, \mathrm{O}, \mathrm{N}, \mathrm{H}$ which could be an atmospheric compound of mass $150 \mathrm{amu}$ with a proton affinity larger than water.

- One contributor to mass $169 \mathrm{amu}$ can be pinonaldehyde. This compound has been identified as a major oxidation product of pinene (Hakola et al., 1994; Yu et al., 1999). Other oxidation products of monoterpenes (MTOP) such as 3-carene, limonene and terpinolene can also contribute to the mass of $169 \mathrm{amu}$ (Hakola et al., 1994). If mass $169 \mathrm{amu}$ is composed of $\mathrm{XH}+$ 
with X being pinonaldehyde or another MTOP, it implies that pinonaldehyde is poorly hydrated, the $n=1$ hydrate (mass $187 \mathrm{amu}$ ) being less abundant than the $\mathrm{n}=0$ hydrate (mass $169 \mathrm{amu}$ ) (Fig. 3). This is consistent with the fact that a similar poor hydration was observed during the calibrations of the other aldehyde (acetaldehyde), which maximum count rate was for the clusters containing only one molecule of water, and with previous observations of poor hydration of saturated aldehydes (Spanel et al., 2002).

Consequently, the most likely candidate compounds contributing to mass 169 amu are MTOP. Moreover, a maximum count rate is observed for mass $173 \mathrm{amu}$ (peak family $47 \mathrm{amu}$ ), with a possible contribution of the type $\mathrm{Z}\left(\mathrm{H}_{2} \mathrm{O}\right)_{2} \mathrm{H}^{+}$, with $\mathrm{Z}$ being mass $136 \mathrm{amu}$, representative of $\alpha$-pinene and other monoterpenes. Mass 136 has already been reported to be an indicator for monoterpenes at forest sites (Helmig et al., 1998; Wisthaler, 2001). Also, selected ion flow tube studies have shown that monoterpenes $\mathrm{M}\left(\alpha\right.$-pinene, $\beta$-pinene, limonene, $\Delta^{3}$-carene, myrcene and camphene) react with $\mathrm{H}_{3} \mathrm{O}^{+}$via proton transfer at the collisional rate and result in the protonated $\mathrm{MH}+$ with mass $\mathrm{m} / \mathrm{z}=137 \mathrm{amu}$ (Schoon et al., 2003). Correlation between the proposed candidates monoterpenes and MTOP are fairly good (Fig. 5b), confirming our hypothesis.

\section{Calibration factors and Reverse reactions (water de- pendence)}

Calibrations have been performed using standard gases bottle (DMA, acetonitrile, acetaldehyde, isoprene and methanol). The intensity of reverse reactions (Eq. 2) can be evaluated from the dependence of calibration factors on the water vapor mixing ratio. For DMA and isoprene, the water dependence of the calibration factor is less than a factor 1.5 between 2000 and $6500 \mathrm{ppm}_{2} \mathrm{O}$ (range of water content during the campaign). For methanol and acetaldehyde though, a clear dependence of the calibration factor on the water content is observed with a high increase up to 25 times less methanol measured than injected at $6000 \mathrm{ppm}$. For acetonitrile, no water dependence is observed below $6000 \mathrm{ppm}_{2} \mathrm{O}$; an abrupt rise is measured for higher water contents but water contents were not higher than $6500 \mathrm{ppm}$ during the QUEST campaign These observations are in agreement with the theory already mentioned, that the closer is the PA of the measured compounds to the PA of water, the more efficient will be the reverse reaction.

Acetone has been calibrated and reverse reactions with water studied with the CIMS apparatus in previous work (Wohlfrom et al., 1999). Calibration factors and water dependance were found to be very similar to the ones found for acetonitrile (in agreement with ther similar PAs).

For other un-calibrated compounds, it is necessary to evaluate if a reverse reaction is possible and significant. From the known PA of compounds studied in this work, we can elaborate a scale of reverse reaction rate coefficients relative to the reverse reactions measured for calibrated compounds. Starting form isoprene (PA of 197), the water dependence is negligible in the range of $3000-6000 \mathrm{ppm}$ of water. Thus also a low reverse reaction is found for DMA (PA of 218-225) and no reverse reaction is expected from compounds such as TMA and MVK+MaCR. However, for ethanol/formic acid (respective PAs of 185.5 and 178) and propanol/acetic acid (respective PAs of 189.4 and 188), a reverse reaction with water can occur and is not taken into account, leading to an underestimation of the mixing ratios calculated in this work. For these compounds, we will only be able to give a lower limit of the concentrations measured in the boreal forest atmosphere. According to the correction applied on calibrated species of equivalent PAs, the uncertainty on the mixing ratios measured for ethanol/formic acid, propanol/acetic acid, can be estimated to be up to a factor 4 for ethanol and high water contents. The lack of data on the PA of pinonaldehyde, other MTOP and monoterpenes make it difficult to evaluate the uncertainty on the mixing ratios calculated in this work, and they have to be considered as lower limits.

\section{Concentrations and daily variations}

Atmospheric trace gas mixing ratios are presented in Table 4, as well as the detection limits calculated as twice the standard deviation on the zero air levels. All compounds but DMA are above the detection limit, the highest mixing ratio is found for acetone, closely followed by mass $168 \mathrm{amu}$ (candidate: MTOP). Variability of the daily variation can be seen on Fig. 6a, on which all data are plotted according to the time of the day; a smoothing procedure over 9 data points has been applyed to make the features clearer. A median diurnal variation has been calculated over the two weeks measuring period as well (Fig. 6b). Two outstanding days are varying significantly from the median concentration (27 and 28 March), these days have been highlighted in Fig. 6 a.

Background mixing ratios of acetone range between $200 \mathrm{pptv}$ in the southern atmosphere and $500 \mathrm{pptv}$ in the Northern atmosphere (Singh et al., 1995). The average mixing ratios measured during the Quest campaign are clearly above background levels, and varied from 1 to $3.5 \mathrm{ppbv}$. Acetone has been measured at similar mixing ratios (1-2 ppbv) over the rain forest (Pöschl et al., 2001), in rural areas in Eastern Canada (around 3 ppbv) (Biesenthal et al., 1998) but also in the upper troposphere (Wohlfrom et al., 1999) and at much higher mixing ratios in urban areas (1-18 ppbv from the Fraser valley, O'Brien et al., 1997). Acetone has both direct emission and secondary photochemical sources in the atmosphere. The major secondary source for acetone in the lower troposphere is the photochemical reaction of the $\mathrm{OH}$ radical and propane (Singh, 1994) and also monoterpenes (Wisthaler et al., 2001). Direct emission sources for acetone 
Table 4. Detection limits calculated as twice the standard deviation of zero air level, and statistics on mixing ratios over the 2-weeks measurements.

\begin{tabular}{lllllllll}
\hline (ppt) & acetone & acetonitrile & acetaldehyde & TMA & DMA & methanol & ethanol/formic acid & propanol/acetic acid \\
\hline Zero air level & 47 & 7.1 & 5.6 & 8.1 & 29.5 & 8.8 & 26.5 & 36.5 \\
Detection limit & 35 & 4.0 & 6.6 & 6.2 & 32.4 & 8.6 & 11 & 18 \\
Mean & 1495 & 75 & 36 & 59 & 12.2 & 334 & 318 & 107 \\
Stdev & 596 & 33 & 31 & 35.5 & 7.7 & 143 & 926 & 104 \\
25ile & 1091 & 51 & 15 & 34 & 7 & 229 & 73 & 34 \\
75 ile & 1655 & 97 & 50 & 79 & 17 & 424 & 259 & 146 \\
median & 1370 & 66 & 33 & 55 & 12 & 330 & 135 & 85 \\
\hline
\end{tabular}

\begin{tabular}{lllll}
\hline $\begin{array}{l}\text { compound X } \\
(68 \mathrm{amu})\end{array}$ & $\begin{array}{l}\text { isoprene/ } \\
\text { compound Y } \\
(70 \mathrm{amu})\end{array}$ & $\begin{array}{l}\text { MVK/MACR/ } \\
(136 \mathrm{amu})\end{array}$ & $\begin{array}{l}\text { monoterpenes } \\
(168 \mathrm{amu})\end{array}$ & MTOP \\
\hline Zero air level & 28.0 & 41 & 181 & 288 \\
Detection limit (ppt) & 12.0 & 11.6 & 87 & 86 \\
Mean & 140 & 185 & 301 & 603 \\
Stdev & 73 & 125 & 139 & 345 \\
25ile & 88 & 104 & 192 & 323 \\
75 ile & 185 & 237 & 401 & 839 \\
median & 120 & 165 & 300 & 605 \\
\hline
\end{tabular}

include anthropogenic and biogenic emissions, including direct emission from vegetation, decaying organic material, biomass burning (Singh et al., 1994) and possibly an oceanic source (Jacob, 2002). Acetone is removed from the atmosphere by photolysis, the reaction with $\mathrm{OH}$ radicals and wet and dry deposition (Jacob, 2002). The acetone diurnal variations show one peak during the morning between 10:00 and 12:00 and one peak during the early night with a maximum around 21:00. As most organic trace gases diurnal profile show a maximum around 21:00, it is believed that the onset of a nocturnal inversion is responsible for their accumulation close to the ground, including acetone. The morning peak can be ascribed to a strong photochemical source (thus related to the radiation diurnal profile), as well as it can be due to direct emissions from vegetation and soil (thus related to the temperature profile).

Isoprene is released to the atmosphere by forest areas in high quantities (i.e. $44 \%$ of the total VOC emissions by vegetation, Guenther et al., 1995). It is highly reactive, its oxidation products being methyl vinyl ketone (MVK) and methacrolein (MaCR) as the highest yield. In Hyytiala, low concentrations are expected because of the type of vegetation, which is composed of poor isoprene emitters (Scots pine and Norway spruce) (Hakola et al., 2003). Isoprene has been reported to have a high seasonal variability, with a maximum during the growing season (from mid-June to mid-september in the boreal zone) (Hakola et al., 2000; Hakola et al., 2003) while its oxidation products MVK and $\mathrm{MaCR}$ remained constant through the year. Isoprene mix- ing ratios reached $6.5 \mathrm{ppbv}$ over the tropical rain forest in March (Warneke et al., 2001) and (isoprene+MBO) 8 ppbv over a Northern american temperate forest in July (Helmig et al., 1998), while the typical mixing ratios of isoprene and (MVK+MACR) measured during Quest were, as expected, much lower: roughly between 100 and 200 pptv. In fact, these mixing ratios are higher than previous measurements of isoprene on the site of Hyytiala (average $41 \mathrm{ppt}$ in august (Spirig et al., 2003) and average 10 pptv in may (Hakola et al., 2000)). This discrepancy can either be due to differences of analytical techniques, or to a contribution of another compound, to the masses selected for the analysis of isoprene. Our MVK+MACR mixing ratios are the same levels as the mass $68 \mathrm{amu}$ mixing ratios (median $165 \mathrm{ppt}$ ). MVK and MaCR have been previously measured with the same level of concentration than isoprene during March 2001 at the SMEAR station (Hakola et al., 2003). Due to its sources and high reactivity with $\mathrm{NO}_{3}$ at night (lifetime $/ \mathrm{NO}_{3}$ is $0.8 \mathrm{~h}$, Seinfeld and Pandis 1998), isoprene is usually measured in the litterature with a diurnal profile showing a maximum at 18:00 LT (Goldan, 1995; Lindinger, 1998; Biesenthal, 1998; Warneke et al., 2001). During the Quest campaign, isoprene showed a diurnal profile with three peaks: one in the morning around 8:00, one in the afternoon around 14:00 and the most important one around 21:00 starting around 18:00. The fact that isoprene reaches a maximum in the first part of the night is in contradiction with the late afternoon peak which is usually observed. For the increase of isoprene up to $21: 00$ to be ascribed to the onset of the 

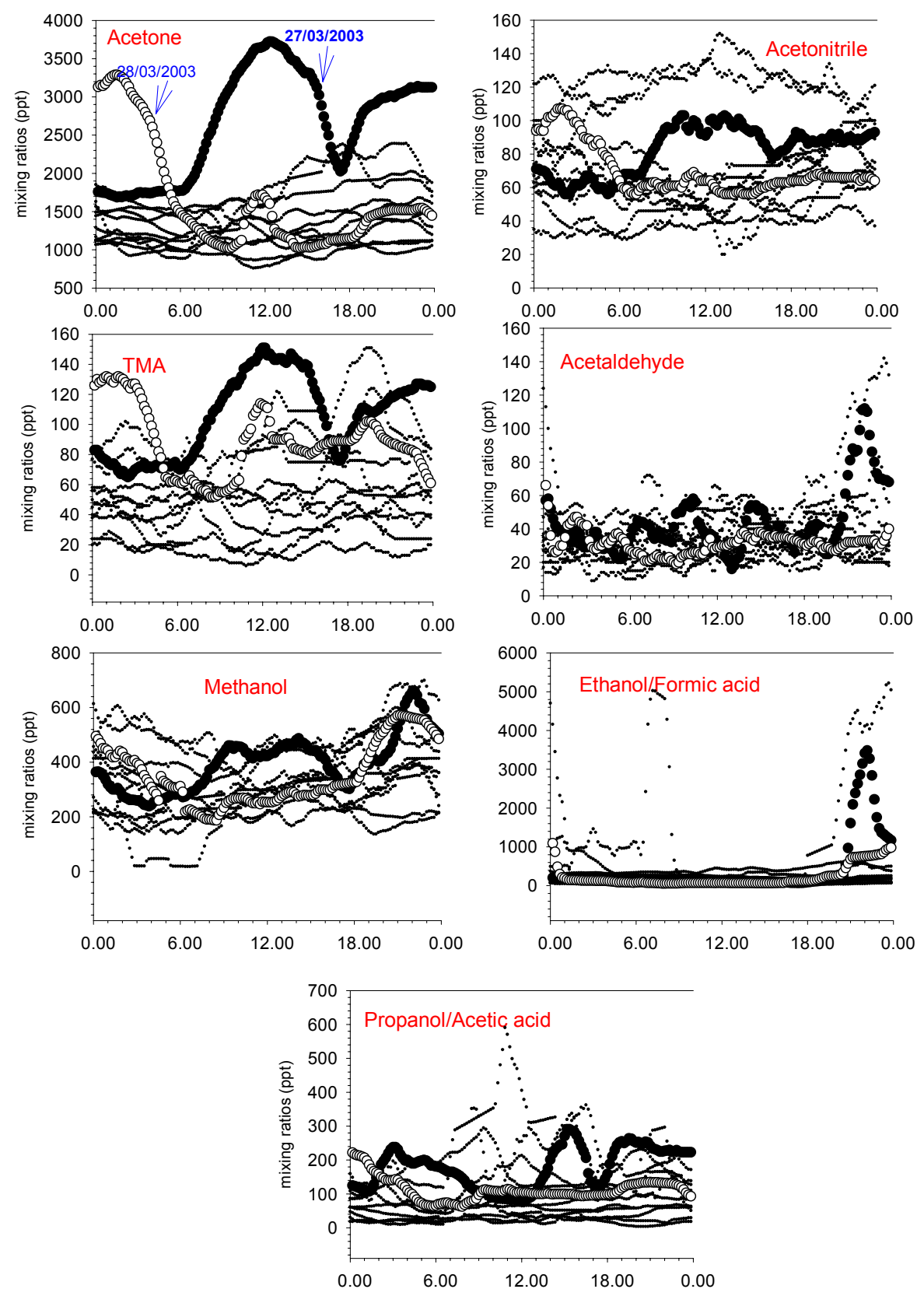

Fig. 6a. (a) Daily variation of mixing ratios for the whole measurement period.

noctural inversion layer, the source of isoprene has to be still active until two hours after sunset, which is improbable. MVK+MACR shows the same pattern as the daily pattern of isoprene, with a more pronounced morning and afternoon peaks and a broader night peak. Because of the level of its mixing ratios, which are high compared to previous measurements on the same site, and because of its diurnal variation, mass $68 \mathrm{amu}+\mathrm{hydrates}$ might contain the contribution of another compound than isoprene, night time emitted. However, we do not have any other candidate for this mass, which seems to be correlated to other biogenic compounds (monoterpenes, MTOP and MVK+MaCR), and hence has probably a biogenic source. It is possible that at night, when isoprene mixing ratios are close to 0 , the contribution from methanol on peak 105 is not negligible. Consequently, we will refer hereafter to mass $68 \mathrm{amu}$ as isoprene+compound $\mathrm{X}$, and, for the same reasons, mass $70 \mathrm{amu}+$ hydrates will be referred to as MVK+MaCR+compound $\mathrm{Y}$.

Mass $136 \mathrm{amu}$ mixing ratios (candidate: monoterpenes) shows a median mixing ratio of $300 \mathrm{ppt}$. Similarly to isoprene, the total monoterpene concentrations usually have a high seasonal variability with a maximum in summer. 

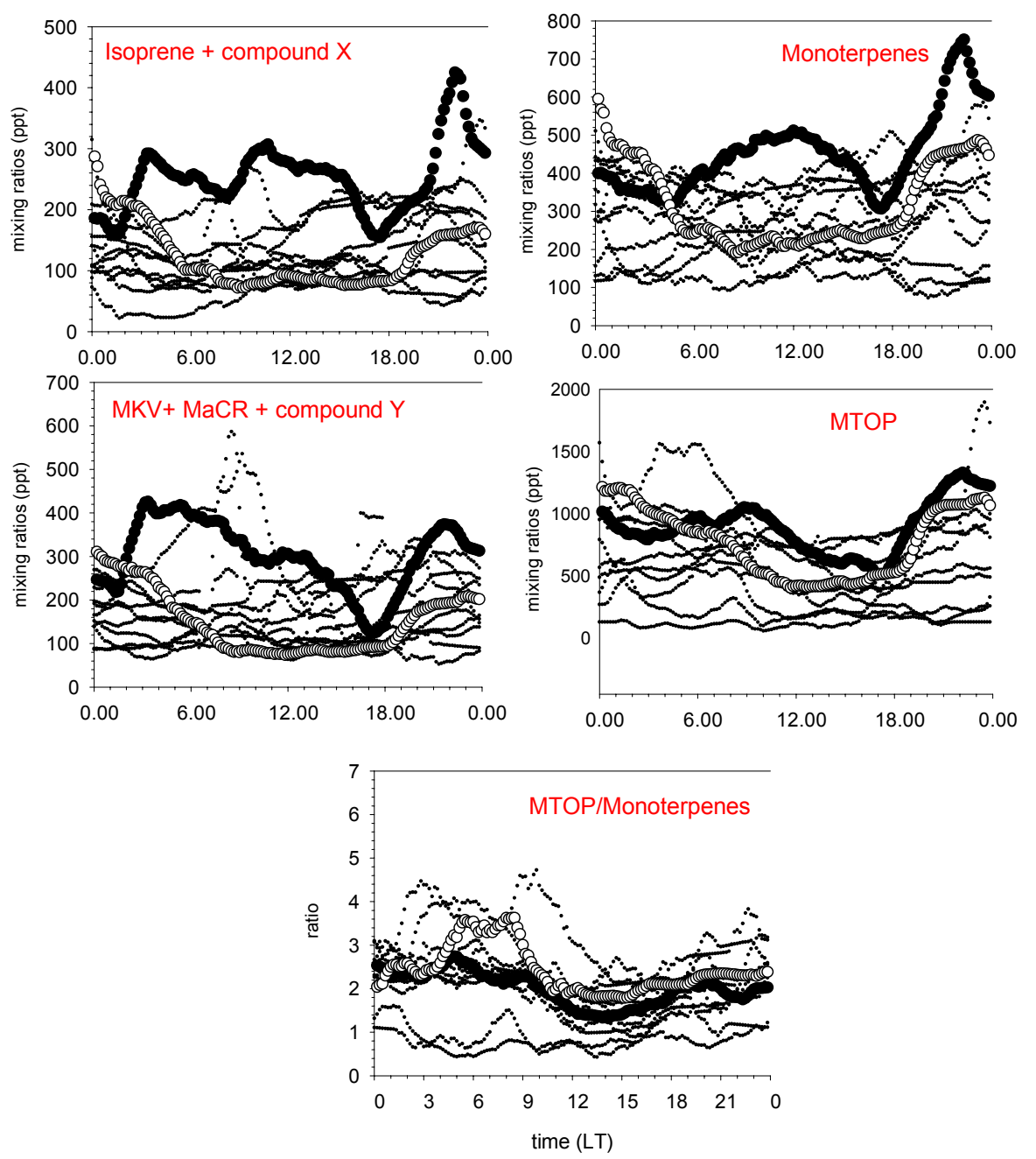

Fig. 6a. Continued.

Typical mixing ratios of around $500 \mathrm{ppt}$ have been measured in April in the boreal forest (Hakola et al., 2000) and $360 \mathrm{ppt}$ have been detected at $18 \mathrm{~m}$ above the ground during BIOFOR2 (Spanke et al., 2001), which lies within the range of our measurements. Spanke et al. (2001) previously measured in Hyyliälä a monoterpene daily variation showing a night time maximum and daytime minimum. We also measure a nighttime maximum although our daily variation is a little bit more complex with also two daily secondary maxima (Fig. 6b).

The MTOP mixing ratios measured in Hyytiälä were in the range $320-840$ pptv, which are the highest mixing ratios measured after acetone. We choose Pinonaldehyde as a representative of those MTOP, as it is a main oxidation product of $\alpha$-pinene, itself main monoterpene detected in the boreal atmosphere (Hakola et al., 2000; Spanke et al., 2003). The main production path of pinonaldehyde is the oxidation of monoterpenes with $\mathrm{O}_{3}$ (Yu et al., 1999) or
$\mathrm{OH}$ radicals. Measured primary yields of pinonaldehyde from the reaction between $\alpha$-pinene and $\mathrm{OH}$ radicals during chamber experiments were higher than the yields of acetone (respectively $30 \%$ and $12 \%$, Wisthaler et al., 2001) and hence, high mixing ratios of pinonaldehyde are expected at the Hyytiala site. However, to our knowledge, atmospheric measurements of MTOP are very scarce and comparison with other sites is difficult. Pinonaldehyde has been measured on the Hyytialä site with maximum concentrations of $140 \mathrm{ppt}$, which indicate that other monoterpene oxidation products comprise a non-negligible part of the MTOP measured with CIMS. As already shown in Fig. 5b, MTOP and monoterpenes are correlated. Figure 6a shows that monoterpenes and MTOP have a similar diurnal variation, also very comparable to "isoprene+compound $\mathrm{X}$ " and "MVK+MaCR+compound Y" showing maximum concentrations early at night. This nighttime maximum of monoterpenes has previously been observed by Lindinger 

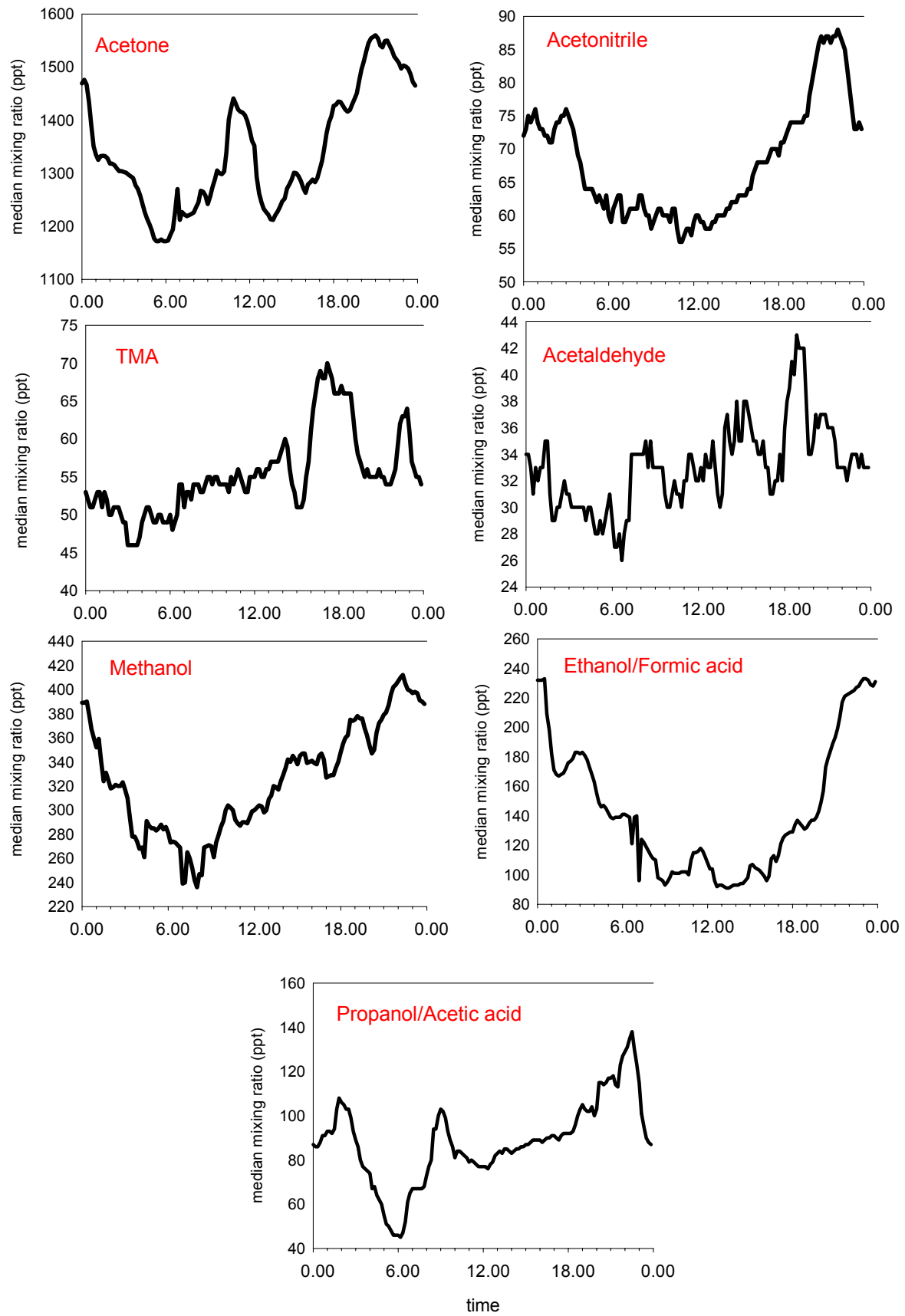

Fig. 6b. (b) Median daily variation of mixing ratios after smoothing procedure (ppt).

at al. (1998) and attributed to emissions by the wood during the day and during the night, but effective dissociation during the day. Monoterpenes nighttime maxima have also bee observed by Hakola et al. (2000) and attributed to trapping of the emitted compounds in a nocturnal inversion layer. Hakola et al. (2000) do not measure any daytime peak, and explain this with a high $\mathrm{OH}$ radical sink and dilution by vertical transport. From our data set, daytime peaks are observed with the same covariation for isoprene+compound X, monoterpenes, $\mathrm{MVK}+\mathrm{MaCR}+$ compound $\mathrm{Y}$ and $\mathrm{CO}$, with a mid-morning decrease of about $3 \mathrm{~h}$. The yield of pinonaldehyde from monoterpenes was estimated to be $48 \%$, and the yield of $\mathrm{CO}$ from pinonaldehyde was estimated to be $13.4 \%$ (Hatakeyma et al., 1991). However, the contribution of the oxidation of other organic compounds should be necessary to explain the change of several tens of ppb in the $\mathrm{CO}$ concentration. Hence, co-variations between $\mathrm{CO}$ and monoterpenes and MTOP are more likely due to dynamics-driven 

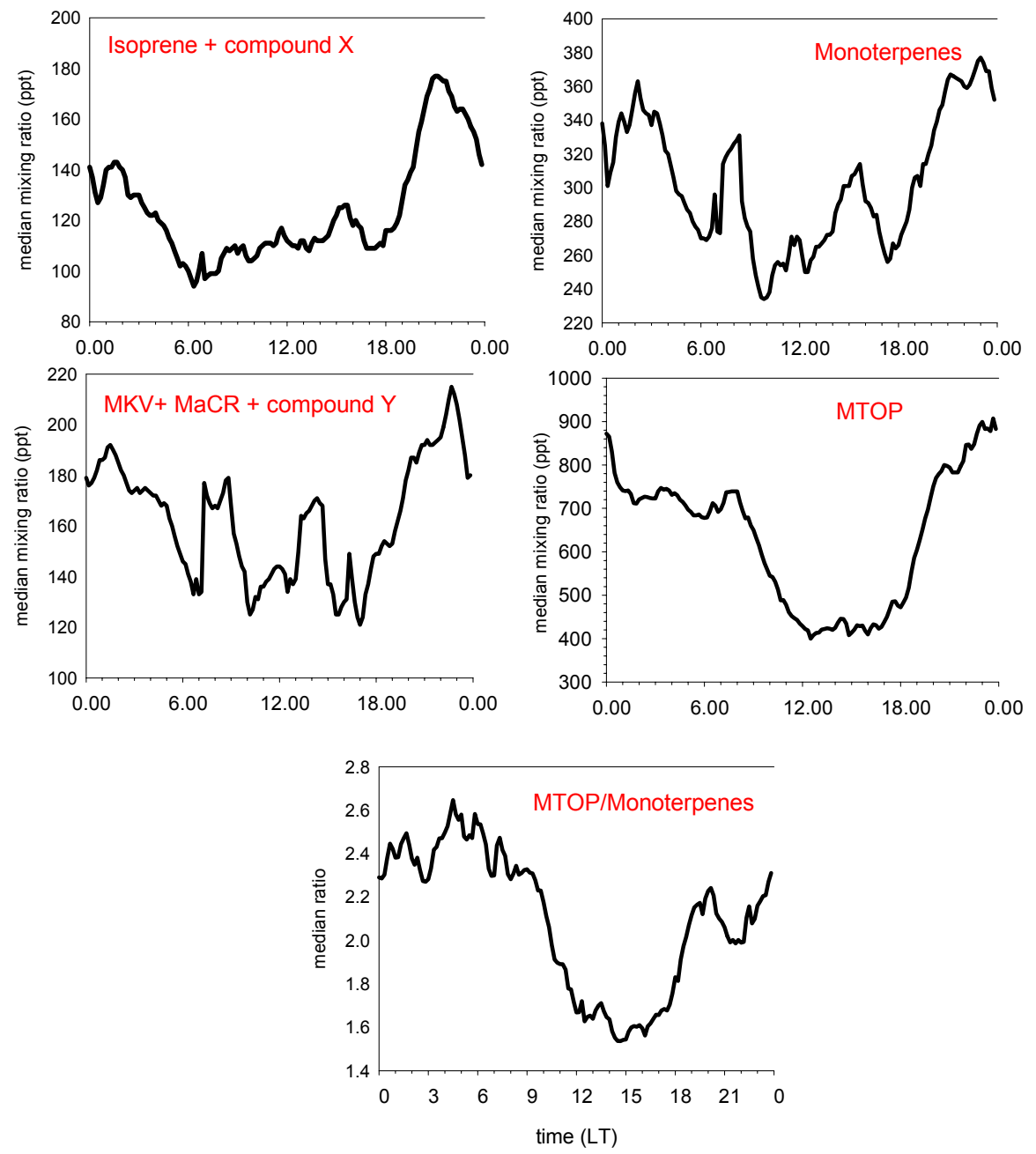

Fig. 6b. Continued.

variations of the concentrations. The daytime peaks of isoprene+compound $\mathrm{X}$, and monoterpenes, are consistent with the diurnal variation of the emissions, which are temperature dependant. Compared to MVK+MaCR+compound $\mathrm{Y}$, MTOP rarely shows a daytime peak though, and might be more rapidely removed in the presence of light. According to Glasius et al. (1997), pinonaldehyde reacts twice as fast as a-pinene with $\mathrm{OH}$ radical which would explain the low daytime mixing ratios of MTOP. Highest concentrations of BVOC oxidation products (and among them pinonaldehyde) have previously been observed to occur in the early morning hours (Spanke et al., 2001). The mid-day depletion is unexplained by photochemistry or dynamics, it is correlated with the increase of acetone, and with the appearance of the particle nucleation burst.

The diurnal variations of the ratio MTOP/monoterpenes show maximum values at night and a sharp morning decrease (Fig. 6a). This is in agreement with the higher reactivity to $\mathrm{OH}$ of pinonaldehyde compared to pinene, as mentioned above.
In the litterature, emission rates of methanol were calculated to be larger than those of isoprene, methanol having a major biogenic source (Lamanna and Goldstein, 1999). Our measurements show mixing ratios varying between 230 and 425 pptv. These ratios are indeed two times higher than the mixing ratios of isoprene+compound $\mathrm{X}$ in Hyytiälä. However, methanol has been reported to be an ubiquitous compound in the atmosphere which levels in remote conditions are around $1 \mathrm{ppbv}$ (de Gouw et al., 2003), which is twice as high as what we measured. Although the high water dependence of methanol due to non negligible reverse reactions has been taken into account with calibrations, the uncertainty on the mixing ratios of this compound are slightly higher than for other compounds, because of the additional uncertainty of the water vapor measurements and of the dependence of the calibration factor. Ethanol/Formic acid and propanol/acetic acid are respectively two and four times lower than methanol. Ethanol/Formic acid concentrations show a high variability (Fig. 6b), and there are indications of a contaminating source in the vincinity of the measurement 
station. However, the contaminations are easily detected and can be excluded. Its median daily variations are similar to the ones of methanol with nighttime maximum and daytime minimum. Propanol/acetic acid do not show the same daily pattern as acetone on the particularly highly concentrated days (27 and 28 March, Fig. 6a), but show a similar median daily pattern then acetone (Fig. 6b), with a mid-day peak and a nighttime maximum.

In remote areas, acetonitrile has been found with mixing ratios of 100-150 pptv (Sprung et al., 2001). The mean mixing ratio found during QUEST is $75 \mathrm{pptv}$, with concentrations main variations between 50 and $100 \mathrm{pptv}$ (25il eand 75ile). The major source of acetonitrile seems to be biomass burning (Holzinger et al., 1999), while anthropogenic fuel burning plays only a minor role (Holzinger et al., 2001). Acetonitrile may therefore serve as a tracer for biomass burning activity. Sinks of acetonitrile are the chemical reaction with $\mathrm{OH}$ radicals, dry or wet deposition. Lifetime against the reaction of $\mathrm{OH}$ and photolysis is of the order of magnitude of 1-3 years, thus much higher than the time scale of the condensing process. The mixing ratios of acetonitrile measured during Quest, found to be lower than mixing ratios in remote areas, would indicate that it is not locally produced. With such a long life time and without any local source, acetonitrile should be rather stable during the day. However, as for methanol and ethanol/formic acid, acetonitrile shows maximum mixing ratios at night and minimum mixing ratios during the day (Fig. 6b). Nighttime maxima of acetonitrile and ethanol can, as for acetone, be explained by the onset of a noctural inversion, together with higher destruction processes during day compared to night.

Mixing ratios of acetaldehyde measured during the campaign range between 15 and $50 \mathrm{pptv}$ (25ile and 75ile). Acetaldehyde is a common photo-oxidation product of many organic compounds in the atmosphere, and itself a precursor of peroxyacetyl nitrate $\left(\mathrm{PAN}, \mathrm{CH}_{3} \mathrm{C}(\mathrm{O}) \mathrm{OONO}_{2}\right)$ in polluted air. Acetaldehyde has one of the shortest day-lifetime of all analyzed compound (after isoprene) and is also destroyed at night by its reaction with $\mathrm{NO}_{3}$, but at a slower rate (night-lifetime/ $\mathrm{NO}_{3}$ is 17 days, Seinfeld and Pandis, 1998). Our daily variation of acetaldehyde are not very pronounced, which, together with the low mixing ratio measured at the site, indicate either the lack of a local source of this compound at the measurement site, or its immediate destruction. From Fig. 6a, there are indications that the contamination source producing ethanol also contained acetaldehyde.

DMA mixing ratios are below the detection limit of 32 pptv, and TMA mixing ratios vary between 34 and 80 pptv. TMA has a late afternoon peak which is not seen in any other compound measured at the site with this technique.

\section{Summary and conclusions}

The goal of this study was to address the different organic compounds measured with the CIMS method during the QUEST campaign. We proposed candidates for the masses observed in the spectra measured in the Boreal atmosphere. Based on the study of their hydrate distribution, methanol, acetonitrile, acetaldehyde, DMA, ethanol/formic acid, acetone, TMA, propanol/acetic acid, isoprene, MVK/MaCR, monoterpenes and MTOP are proposed in a first step as candidates for masses 32, 41, 44, 45, 46, 58, 59, 60, 68 70, 136 and $168 \mathrm{amu}$, respectively.

Concentrations of acetone are in the range of the concentrations found in the litterature in forest areas, and acetonitrile in the range of concentrations found in remote areas. Methanol is measured with mixing ratios two times higher than in the remote regions, ethanol//formic acid and propanol/acetic acid are measured with concentrations respectively two and four times lower than methanol. Amines are found with the lowest concentrations.

However, the high hydration level of the analyzed compounds makes interferences with other compounds more likely. While monoterpenes have been measured with similar mixing ratios than previously found at the same site and same season, isoprene concentrations were about an order of magnitude higher and their daily variations do not show the usual pattern of a late afternoon maximum. Hence, most probably, isoprene is measured with the interference of a yet unknown biogenic, night-emitted compound $\mathrm{X}$.

In fact, all of the measured organic trace gases but TMA show higher mixing ratios at night, in agreement with measurements of independent measurements of $\mathrm{CO}$ (Sellegri et al., this issue). This is ascribed to the onset of a noctural inversion, coupled with continuous emmision by the forest into the night and higher dissociation during the day. In particular, oxidation products of monoterpenes and isoprene+compound $\mathrm{X}$ are significantly higher at night, implying that an active $\mathrm{NO}_{3}$ chemistry is also taking place. In fact, the ratio $\mathrm{MTOP} /$ monoterpenes are higher at night by a factor 1,5. Daytime peaks are observed with the same covariation for isoprene+compound $\mathrm{X}$, monoterpenes, $\mathrm{MVK} / \mathrm{MaCR}$ and $\mathrm{CO}$, with a mid-morning decrease of about 3 hours. The covariance may be indicative of a local important production of $\mathrm{CO}$, or may be indicative that the dynamics of the boundary layer are the main factor influencing the organic concentrations on the site. The mid-day depletion may be indicative of a condensing process coinciding with the appearance of nucleation bursts.

This paper is preparing for further discussions on the implications that the detection of these species have on the atmospheric physics and particularly on the formation or growth of new particles in the boreal forest atmosphere. This matter is addressed in a companion paper (Sellegri et al., this issue). 
Acknowledgements. The QUEST project was funded by the European Community, contract Nb EVK2-CT-2001-00127. The authors are very grateful to B. Preissler and R. Zilly for their participation to the instrumental set up, to G. Eerdekens for supporting work in the lab, and wish to thank H. Hakola for helpful discussions.

Edited by: K. Hämeri

\section{References}

Atkinson, R.: Gas phase tropospheric chemistry of organic compounds, J. Phys. Chem. Ref. Data Monogr., 2, 1-216, 1994.

Biesenthal, T. A., Bottenheim, J. W., Shepson, P. B., Li, S.-M., and Brickell, P. C.: The chemistry of biogenic hydrocarbons at a rural site in eastern Canada, J. Geophys. Res., 103, 25 487-25 498, 1998.

De Gouw, J., Warneke, C., Karl, T., Eerdekens, G., Van der Veen, C., and Fall, R.: Sensitivity and specificity of atmospheric trace gas detection by proton-transfer-reaction mass spectrometry, Int. J. Mass Spectr., 223-224, 365-382, 2003.

Glasius, M., Calogirou, A., Jensen, N. R., Hjorth, J., and Nielsen, C. J.: Kinetic study of gas-phase reactions of pinonaldehyde and structurally related compounds, Int. J. Chem. Kin., 29, 527-533, 1997.

Goldan, P. D., Kuster, W., and Fehesenfeld, F.: The observation of a C5 alcohol emission in North American pine forest, Geophys. Res. Lett., 20, 1039-1042, 1993.

Guenther, A., Hewitt, C. N., Erickson, D., Fall, R., Geron, C., Graedel, T., Harley, P., Klinger, L., Lerdau, M., McKay, W. A., Pierce, T., Scholes, B., Steinbrecher, R., Tallamraju ,R., Taylor, J., and Zimmerman, P.: A global model of nature volatile organic compound emissions, J. Geophys. Res., 100, 8873-8892, 1995.

Hakola, H., Arey, J., Aschmann, S. M., and Atkinson, R.: Product formation from the gas-phase reactions of $\mathrm{OH}$ radicals and $\mathrm{O}_{3}$ with a series of monoterpenes, J. Atmos. Chem., 18, 75-102, 1994.

Hakola, H., Laurina, T., Rinne, J., and Puhto, K.: The ambient concentrations of biogenic hydrocarbons at a northern European, boreal site, Atmos. Environ., 34, 4971-4982, 2000.

Hakola, H., Tarvainen, V., Laurina, T., Hiltunen, V., Hellen, H., and Keronen, P.: Seasonal variation of VOC concentrations above a boreal coniferous forest, Atmos. Environ., 37, 1623-1634, 2003.

Hanke, M., Umann, B., Uecker, J., Arnold, F., and Bunz, H.: Atmospheric measurements of gas-phase $\mathrm{HNO}_{3}$ and $\mathrm{SO}_{2}$ using chemical ionization mass spectrometry during the MINATROC field campaign 2000 on Monte Cimone, Atmos. Chem. Phys., 3, 417436, 2003,

\section{SRef-ID: 1680-7324/acp/2003-3-417.}

Hatakeyma, S., Izumi, K., Fukuyama, T., Akimoto, H., and Washida, N.: Reactions of $\mathrm{OH}$ with $\alpha$-pinene and $\beta$-pinene in air: Estimate of global CO production from the atmospheric oxidation of terpenes, J. Geophys. Res., 96, 947-958, 1991.

Helmig, D., Greenberg, J., Guenther, A., Zimmerman, P., and Geron, C.: Volatile organic compounds and isoprene oxidation products at a temperate deciduous forest site, J. Geophys. Res., 103, 22 397-22 414, 1998.

Hoffman, T., Odum, J. R., Bowman, F., Collins, D., Klockov, D., Flagan, R. C., and Seinfeld, J. H.:, Formation of organic aerosols from the oxidation of biogenic hydrocarbons, J. Atmos. Chem., 26, 189-222, 1997.

Holzinger, R., Warneke, C., Hansel, A., Jordan, A., Lindinger, W., Scharffe, D. H., Schade, G., and Crutzen, P. J.: Biomass burning as a source of formaldehyde, acetaldehyde, methanol, acetone acetonitrile, and hydrogen cyanide, Geophys. Res. Lett., 26, 1161-1164, 1999.

Holzinger, R., Jordan, A., Hansel, A., and Lindinger, W.: Automobile emissions of acetonitrile: assessment of its contribution to the global source, J. Atmos. Chem., 38, 187-193, 2001.

Jacob, D. J., Field, B. D., Jin, E. M., Bey, I., Li, Q., Logan, J. A., Yantosca, R., and Singh, H. B.: Atmospheric budget of acetone, J. Geophys. Res., 107, D10, 4100, doi:10.1029/2001JD000694, 2002.

Karl, T. G., Spirig, C., Rinne, J., Stroud, C., Prevost, P., Greenberg, J., Fall, R., and Guenther, A.: Virtual disjunct eddy covariance measurements of organic compound fluxes from a subalpine forest using proton transfer reaction mass spectrometry, Atmos. Chem. Phys., 2, 279-291, 2002

SRef-ID: 1680-7324/acp/2002-2-279.

Keesee, R. and Castleman, A.: Thermodynamic data on gasphase ion-molecule association and clustering reactions, J. Phys. Chem. Ref. Data, 15, 1011-1071, 1986.

Kulmala, M., Hameri, K., Aalto, P. P., Makela, J. M., Pirjola, L., Nilsson, D., Buzorius, G., Rannik, U., Dal Maso, M., Seidl, W., Hoffman, T., Janson, R., Hansson, H.-C., Viisanen, Y., Laaksonen, A., and O'Dowd, C.: Overview of the international project on biogenic aerosol formation in the boreal forest (BIOFOR), Tellus 53B, 324-343, 2001.

Lamanna, M. S. and Goldstein, A. H.: In situ measurements of C2-C10 volatile organic compounds above a Sierra Nevada ponderosa pine plantation, J. Geophys. Res., 104, 21 247-21 262, 1999.

Lindinger, W., Hansel, A., and Jordan, A.: On-line monitoring of volatile organic compounds at pptv levels by means of ProtonTransfer-Reaction Mass Spectrometry (PTR-MS) Medical applications, food control and environmental research, Int. J. Mass Spect. Ion Proc., 173, 191-241, 1998.

O'Brien, J. M., Shepson, P. B., Wu, Q., Biesenthal, T., Bottenheim, J. W., Wiebe, H. A., Anlauf, K. G., and Brickell, P.: Production and distribution of organic nitrates, and their relationship to carbonyl compounds in an urban environment, Atmos. Environ., 31, 2059-2069, 1997.

Pöschl, U., Williams, J., Hoor, P., Fischer, H., Crutzen, P. J., Warneke, C., Holzinger, R., Hansel, A., Jordan, A., Lindinger, W., Scheeren, H. A., Peters, W., and Lelieveld, J.: High acetone concentrations throughout the $0-12 \mathrm{~km}$ altitude range over the tropical rain forest in Surinam , J. Atmos. Chem., 38, 115-132, 2001.

Schoon, N., Amelynck, C., Vereecken, L., and Schoon, E. A.: A selected ion flow tube study of the reactions of $\mathrm{H}_{3} \mathrm{O}^{+}, \mathrm{NO}^{+}$and $\mathrm{O}_{2}^{+}$with a series of monoterpenes, 229, 231-240, 2003.

Schröder, D., Soldi-Lose, H., Semialjac, M., Loos, J., Schwarz, H., Eerdekens, G., and Arnold, F.: On gaseous $\mathrm{C}_{4} \mathrm{H}_{6} \mathrm{O}_{2}$ compounds in the atmosphere: new insights from collision in the laboratory and on aircraft, Int. J. of Mass Spectr., 228, 35-47, 2003.

Seinfeld, J. H. and Pandis, S. N.: Atmospheric chemistry and physics, John Wiley and Sons, New York, 1998. 
Sellegri, K., Hanke, M., Umann, U., Arnold, F., and Kulmala, M.: Measurements of Organic Gases during Aerosol Formation Events in the Boreal Forest Atmosphere during QUEST, Atmos. Chem. Phys., 5, 373-384, 2005,

SRef-ID: 1680-7324/acp/2005-5-373.

Singh, H. B., O'Hara, D., Herlth, D., Sachse, W., Blake, D. R., Bradshaw, J. D., Kanakidou, M., and Crutzen, P. J.: Acetone in the atmosphere: distribution, sources and sinks, J. Geophys. Res., 99, 1805-1819, 1994.

Singh, H. B., Kanakidou, M., Crutzen, P. J., and Jacob, D. J.: High concentrations and photochemical fate of oxygenated hydrocarbons in the global troposphere, Nature, 378, 50-54, 1995.

Spanel, P., Van Doren, J. M., and Smith, D.: A selected ion flow tube study of the reactions of $\mathrm{H}_{3} \mathrm{O}^{+}, \mathrm{NO}^{+}$, and $\mathrm{O}_{2}^{+}$with saturated and unsaturated aldehydes and subsequent hydration of the product ions, Int. J. Mass Spect., 213, 163-176, 2002.

Spanke, J., Rannik, U., Forkel, R., Nigge, W., and Hoffman, T.: Emission fluxes and atmospheric degradation of monoterpenes above a boreal forest: field measurements and modeling, Tellus, 53B, 406-422, 2001.

Spaulding, R. S., Schade, G. W., Goldstein, A. H., and Charles, M. J.: Characterization of secondary atmospheric photooxidation products : Evidence for biogenic and anthropogenic sources, J. Geophs. Res., 108, D8, 2003.

Spirig, C., Guenther, A., Greenberg, J. P., Calanca, P., and Tarvainen, V.: Tethered balloon measurements of volatile organic compounds at a boreal forest site, Atmos. Chem. Phys., 4, 215229, 2004,

SRef-ID: 1680-7324/acp/2004-4-215.

Sprung, D., Jost, C., Reiner, T., Hansel, A., and Wisthaler, A.: Acetone and acetonitrile in the Tropical Indian Ocean boundary layer and free troposphere: aircraft-based intercomparison of AP-CIMS and PTR-MS measurements, J. Geophys. Res., 106, 28 511-28 527, 2001.
Viggiano, A. A., Dale, F., and Paulson, J. F.: Proton transfer reactions of $\mathrm{H}+(\mathrm{H} 2 \mathrm{O}) \mathrm{n}=2-11$ with methanol, ammonia, pyridine, acetonitrile and acetone, J. Chem. Phys., 88, 2469-2477, 1988.

Warneke, C., Holzinger, R., Hansel, A., Jordan, A., Lindinger, W., Pöschl, U., Williams, J., Hoor, P., Fisher, H., Crutzen, P. J., Sheeren, H. A., and Lelieveld, J.: Isoprene and its oxidation products methyl vinyl ketone, methacrolein, and isoprene related peroxides mesaured online over the tropical rain forest of Surinam in March 1998, J. Atmos. Chem., 38, 167-185, 2001.

Williams, J., Fisher, H., Harris, G. W., Crutzen, P. J., Hoor, P., Hansel, A., Holzinger, R., Warneke, C., Lindinger, W., Scheeren, B., and Lelieveld, J.: Variability-lifetime relationship for organic trace gases: a novel aid to compound identification and estimation of OH concentrations, J. Geophys. Res., 105, 20 473-20 486, 2000.

Wisthaler, A., Jensen, N. R., Winterhalter, R., Lindinger, W., and Hjorth, J.: Measurements of acetone and other gas phase product yields from the $\mathrm{OH}$-initiated oxidation of terpenes by protontransfer-reaction mass spectrometry (PTR-MS), Atmos. Environ., 35, 6181-6191, 2001.

Wohlfrom, K.-H.: Measurements of atmospheric trace gases and ions by aircraft-based mass spectrometers: New insights into ozone, aerosols, and the impact of air traffic on the atmosphere, PhD Thesis, Heidelberg, Germany, 2000.

Wohlfrom, K.-H., Hauler, T., Arnold, F., and Singh, H.: Acetone in the free troposphere and the lower stratosphere: aircraft-based CIMS and GC measurements over the North Atlantic and a first comparison, Geophys. Res. Let., 26, 2849-2852, 1999.

Yu, J., Griffin, R. J., Cocker III, D. R., Flagan, R. C., and Seinfeld, J. H.: Observation of gaseous and particulate products of monoterpene oxidation in forest atmospheres, Geophys. Res. Lett., 26, 1145-1148, 1999.

Yu, J., Cocker III, D. R., Griffin, R. J., Flagan, R .C., and Seinfeld, J. H.: Gas-phase ozone oxidation of monoterpenes: gaseous and particulate products, J. Atmos. Chem., 34, 207-258, 1999. 